\title{
ESTABLISHING A FIRM CHRONOLOGICAL FRAMEWORK FOR NEOLITHIC AND EARLY DYNASTIC ARCHAEOLOGY IN THE SHANGLUO AREA, CENTRAL CHINA
}

\author{
Yizhi Zhu ${ }^{1,2} \cdot$ Peng Cheng ${ }^{1,3} \cdot$ Shi-Yong $\mathrm{Yu}^{1} \cdot$ Huagui $\mathrm{Yu}^{1,4} \cdot$ Zhihai Kang $^{1,3} \cdot$ Yachang Yang $^{5} \bullet$ \\ A J T Jull $\bullet$ T Lange ${ }^{6} \cdot$ Weijian Zhou ${ }^{1,3,7}$
}

\begin{abstract}
Technological and theoretical advancements in modern radiocarbon chronology make the precise dating of archaeological and geological events possible. Here, we show examples of how these state-of-the-art methods can be used to establish and refine the archaeological cultural chronology for the Shangluo area in the Qinling Mountains of central China. In this study, the Donglongshan and Zijing sites were dated using the high-precision accelerator mass spectrometry (AMS) ${ }^{14} \mathrm{C}$ method. Also, detailed magnetic-susceptibility measurements were conducted at both sites to gain preliminary information about past climate changes. The ${ }^{14} \mathrm{C}$ dates, after being treated with Bayesian statistics, provide a firm constraint on the archaeological chronological framework for this area. Within this framework, the Malan loess-Holocene soil transition can be placed at 10,400-10,090 BC, while the duration of the Yangshao and Longshan cultures was dated to $\sim 4200-2900$ and $\sim 2900-2100$ BC, respectively, revealing an undisrupted history of human occupation in this area until the early dynastic period. Magnetic susceptibility values began to increase in the early Holocene, indicating a progressive amelioration of regional climate. The widespread development of paleosol during the middle Holocene indicates that warm and wet climate conditions prevailed, providing a favorable environmental context within which the Yangshao culture thrived. Magnetic susceptibility values then decreased from $\sim 2100$ BC when the Xia Dynasty started, and loess accumulated again, pointing to cooling and drying climate conditions that may have led to a cultural transition from the Neolithic to the dynastic civilization.
\end{abstract}

\section{INTRODUCTION}

Radiocarbon dating, as a precise chronological method, has been being widely used to determine the absolute age of geological and archaeological strata. The emergence of AMS (accelerated mass spectrometry) opens new avenues for the application of this method in archaeological and geological sciences. For example, a state-of-the-art AMS facility can yield precise ${ }^{14} \mathrm{C}$ dates of samples containing trace amounts (e.g. $\sim 1 \mathrm{mg}$ ) of organic carbon, making non-intrusive dating of invaluable archaeological samples possible. In addition to this technical advancement, there appears to be an increasing use of Bayesian statistics in ${ }^{14} \mathrm{C}$ chronologies, including tree-ring calibration of ${ }^{14} \mathrm{C}$ dates (e.g. Buck et al. 1991, 1992, 2006; Christen and Litton 1995; Goslar and Madry 1998; Bronk Ramsey et al. 2001; Aguilar et al. 2002; Bronk Ramsey 2009), as well as age-depth modeling (e.g. Christen et al. 1995; Blaauw and Christen 2005; Blaauw et al. 2007; Bronk Ramsey 2008).

Software developed in a Bayesian paradigm, e.g. OxCal (Bronk Ramsey 1995, 2001) and BCal (Buck et al. 1991), can usually give a more accurate representation of the age than those following a frequentist viewpoint (e.g. the intercept method). This is because Bayesian statistics is capable of making use of some a priori information (e.g. stratigraphic order of the ${ }^{14} \mathrm{C}$ dates or their approximate calendar ages determined independently from other indicators in the tree-ring calibration process; Bayliss et al. 2007a,b; Navarro 2005; Nicholls and Jones 2001) in order to more precisely pinpoint possible age ranges. For example, $\mathrm{OxCal}$ and $\mathrm{BCal}$ can give a much narrower probability distribution of the calibrated ages, if the stratigraphically ordered ${ }^{14} \mathrm{C}$ dates were dealt with simultaneously rather than individually (Zeidler et al. 1998; Steier and Rom 2000; Palonen and Tikkanen

\footnotetext{
${ }^{1}$ State Key Laboratory of Loess and Quaternary Geology, Institute of Earth Environment, CAS, Xi'an 710075, China.

${ }^{2}$ Corresponding author. Email: zhyz@loess.1lqg.ac.cn.

${ }^{3}$ Xi' an AMS Center, Xi'an 710072, China.

${ }^{4}$ Institute of Shannxi Yanchang Petroleum (Group) Co. Ltd., Xi'an 710075, China.

${ }^{5}$ Shaanxi Archaeology Institute, Xi' an 710054, China.

${ }^{6}$ NSF Arizona AMS Facility, University of Arizona, Tucson, Arizona 85721, USA.

${ }^{7}$ Xi'an Jiao Tong University, Xi'an 710049, China.
}

(C) 2010 by the Arizona Board of Regents on behalf of the University of Arizona

Proceedings of the 20th International Radiocarbon Conference, edited by A J T Jull

RADIOCARBON, Vol 52, Nr 2-3, 2010, p 466-478 
2007). This is particularly important for dating short-lived events, e.g. volcanic eruptions (Buck et al. 2003; D Lowe et al. 2007; J Lowe et al. 2008; Petrie and Torrence 2008) and earthquakes (Scharer et al. 2007), if more ${ }^{14} \mathrm{C}$ dates are available from the surrounding levels of interests.

In conjunction with systematic ${ }^{14} \mathrm{C}$ dating, Bayesian statistics has exhibited great potential in refining archaeological chronology (Blackwell and Buck 2003; Fuller et al. 2007; Beramendi-Orosco et al. 2009; Higham and Higham 2009). However, the advantage of this method has not been widely appreciated in the archaeological communities yet, and there are only very a few studies that have made use of this method in China (e.g. Xia-Shang-Zhou Dating Project Group 2000; Zhang et al. 2007; Boaretto et al. 2009). Given the long history of human settlement in China, precise dating of cultural sequences at some key archaeological sites is of great importance for understanding the origin and dispersion of agriculture as well as the emergence and development of complex society.

The Qingling Mountains of central China has a long history of human occupation from the Neolithic Age onwards (Yang 2003). Archaeological excavations in this area since the 1980s revealed a continuous human occupation (Library of Shang County and Banpo Museum of Xian 1981), as indicated by gradual and uninterrupted changes in artifact assemblages. However, the regional cultural sequence has not been well constrained due to the lack of systematic ${ }^{14} \mathrm{C}$ dating, and the continuity of cultural changes in this area has not been verified using other geoarchaeological proxies. Here, we aim at establishing a reliable chronological framework for the regional archaeology based on detailed AMS ${ }^{14} \mathrm{C}$ dating of soil and charcoal samples collected from 2 cultural sites in the Shangluo area. Bayesian analyses were also performed on the ${ }^{14} \mathrm{C}$ dates to obtain refined tree-ring calibrated ages using the computer program OxCal (Bronk Ramsey 1995, 2001).

\section{CULTURAL AND PHYSICAL SETTINGS}

Shangluo $\left(108^{\circ} 34^{\prime} 20^{\prime \prime}\right.$ to $111^{\circ} 1^{\prime} 25^{\prime \prime} \mathrm{E}, 33^{\circ} 25^{\prime} 40^{\prime \prime}$ to $\left.34^{\circ} 25^{\prime} 40^{\prime \prime} \mathrm{N}\right)$ is located in the upper Danjiang River area of the Qinling Mountains, central China. Archaeologically, this area is marked by a transition zone from Yellow River to the Yangtze River cultural types, as indicated by the typology of the artifacts. From the Neolithic onwards, the regional archaeological cultures developed continuously, as marked by a gradual transition from the Neolithic Laoguantai (6500-5000 BC), Yangshao (5000-3000 BC), and Longshan (3000-2000 BC) cultures to the dynastic Xia ( 2100-1600 BC), Shang ( 1600-1100 BC), and Zhou ( 1100-256 BC) cultures (Yang 2003). This uninterrupted cultural sequence is of great importance for understanding the rise and fall of human civilization and the possible connection with Holocene climatic changes. However, little is known about the precise timing of this archaeological cultural sequence, particularly the existence of the Xia Dynasty, which remains as one of the most significant debates in the international archaeological community.

Climatologically, this area lies on the boundary between the warm temperate and the subtropical zones. The mean annual temperature is $\sim 12.9^{\circ} \mathrm{C}$, and mean annual precipitation is $\sim 750 \mathrm{~mm}$. The annual number of frost-free days is 206 . The natural vegetation is dominated by mixed forests with deciduous broadleaved and coniferous trees. According to our geological investigations in this area over the years, exposure of loess-paleosol sequences are common on the second and third terraces of the Danjiang River. These sediment sequences are usually $\sim 2 \mathrm{~m}$ thick and are composed of 2 distinct lithic units: the lower one is loess-like sediments, while the upper one is a paleosol dual complex containing abundant remains of human activities such as colored potsherds and charcoal. In collaboration with the Archaeological Institute of Shaanxi Province, the Donglongshan $\left(109^{\circ} 49^{\prime} \mathrm{E}\right.$, $\left.33^{\circ} 52^{\prime} \mathrm{N}\right)$ and $\mathrm{Zijing}\left(109^{\circ} 50^{\prime} \mathrm{E}, 33^{\circ} 51^{\prime} \mathrm{N}\right)$ sites were excavated and studied following a multidisciplinary approach. Detailed archaeological and geological data related to Holocene vegetation and environmental changes will be published elsewhere. Here, we only focus on the chronological issue. 


\section{MATERIAL AND METHODS}

\section{Sampling and Pretreatments}

To gain a better stratigraphic perspective of these 2 sites, archaeological trenches were excavated at the margin of the sites in collaboration with the Archaeological Institute of Shaanxi Province in 2007. Magnetic susceptibility was measured at 2 -cm intervals in the field using a portable handheld magnetometer along the cleaned exposure at both sites. Charcoal and bulk soil samples were collected at certain depths. Both charcoal and bulk soil samples were dated in this study. Charcoal is derived from the incomplete combustion of terrestrial plants used by the colonizers as fuel, and thus is not subject to reworking. Therefore, it is an ideal material for ${ }^{14} \mathrm{C}$ dating and can provide precise age constraints for the archaeological cultural sequence. The samples of charcoal were treated using the conventional acid-alkali-acid method. First, the samples were rinsed with deionized water, and treated with $1 \mathrm{~N} \mathrm{HCl}$ in a water bath at constant temperature $\left(60^{\circ} \mathrm{C}\right)$ for $2 \mathrm{hr}$ to remove carbonates. The samples were rinsed repeatedly with deionized water to get rid of excess $\mathrm{HCl}$, and then treated with $1 \mathrm{~N} \mathrm{NaOH}$ in a water bath for another $2 \mathrm{hr}$ to ensure a complete removal of humic and fulvic acid. For some samples, this procedure was repeated several times until the supernatant looked clear. The samples were rinsed repeatedly with deionized water until neutral and $1 \mathrm{~N} \mathrm{HCl}$ was added to the samples to neutralize any remaining $\mathrm{NaOH}$. The samples were rinsed repeatedly with deionized water again until neutral, and then dried in an electric oven at $60^{\circ} \mathrm{C}$.

The bulk soil samples were treated in a slightly different way. Detailed procedures are given in Zhou et al. $(1990,1992)$. First, the soil samples were soaked in deionized water overnight, then transferred to an ultrasonic bath for 30 min to completely disintegrate and homogenize them. The wet samples were sieved using a $180-\mu \mathrm{m}$ mesh to get rid of root fragments. Then, $1 \mathrm{M} \mathrm{HCl}$ was added to the samples, and they were placed in a water bath at $70^{\circ} \mathrm{C}$ for $2 \mathrm{hr}$ to remove carbonates. The samples were rinsed repeatedly until neutral, then dried overnight in an electric oven at $60^{\circ} \mathrm{C}$. Finally, the desiccated samples were transferred into glass vials and sealed tightly for subsequent combustion and graphitization.

\section{Combustion and Graphitization}

Conventional combustion and step combustion were used to obtain $\mathrm{CO}_{2}$ gas for charcoal and bulk soil samples, respectively. For conventional combustion, a subsample of the charcoal $(\sim 5 \mathrm{mg})$ along with cuprous oxide was placed in a quartz tube and evacuated using a high vacuum system. $(\mathrm{CuO}$ mass was determined using the equation $\mathrm{m}_{\mathrm{CuO}}=\%$ yield $\times \mathrm{m}_{\mathrm{s}} \times 100$, where $\%$ yield is the approximate carbon content of the sample, and $\mathrm{m}_{\mathrm{s}}$ is the mass of the subsample.) Once the vacuum level reached $-1 \times 10^{-5}$ Torr, the sample tube was isolated from the vacuum line. The sample was combusted using a natural gas jet burner for about $20 \mathrm{~min}$ and the resulting gas was then passed through several cleaning elements to purify it. The purified $\mathrm{CO}_{2}$ was then collected using liquid nitrogen and reduced to graphite for AMS dating.

Soil samples underwent step combustion at 400 and $900{ }^{\circ} \mathrm{C}$ to ensure a thorough deliberation of $\mathrm{CO}_{2}$ from different components of the total organic matter. Most of organic matter can be burnt at $400{ }^{\circ} \mathrm{C}$. First, samples were combusted at $400{ }^{\circ} \mathrm{C}$ to obtain $\mathrm{CO}_{2}$ from the volatile organic component. Then, we increased the temperature to $900^{\circ} \mathrm{C}$. At $900{ }^{\circ} \mathrm{C}$, the organic matter included in the lattice of some minerals will be released. Note that we did not go beyond $900{ }^{\circ} \mathrm{C}$, as most of the calcium carbonate minerals will be decomposed above this temperature and thus $\mathrm{CO}_{2}$ from inorganic carbon will be released. First, a subsample of the soil $(\sim 500 \mathrm{mg})$ was put into the quartz tube and evacuated to $-1 \times$ $10^{-5}$ Torr using a high vacuum system. Once the desired vacuum level was achieved, the sample tube 
was isolated from the vacuum line, and 12 Torr of high-purity oxygen was introduced. The sample was then combusted using an electrical furnace at $400{ }^{\circ} \mathrm{C}$ for $30 \mathrm{~min}$. The liberated $\mathrm{CO}_{2}$ was purified, collected using liquid nitrogen, and reduced to graphite for AMS dating. The entire vacuum system was again evacuated to $10^{-5} \mathrm{Torr}$, and purified oxygen was introduced into the sample tube. The sample was then combusted using an electric furnace at $900{ }^{\circ} \mathrm{C}$ for $20 \mathrm{~min}$. The liberated $\mathrm{CO}_{2}$ was purified, collected using liquid nitrogen, and reduced to graphite for AMS dating.

The $\mathrm{Zn} / \mathrm{Fe}$ catalytic reduction method was employed for the preparation of graphite targets in this study. The residual radioactivity of the samples with respect to that of the modern ${ }^{14} \mathrm{C}$ standard was measured in the Xi'an AMS Center of the Chinese Academy of Sciences. For this work, we used China's sugar beat carbon as the modern ${ }^{14} \mathrm{C}$ standard, which in turn was converted to the international modern ${ }^{14} \mathrm{C}$ standard (i.e. oxalic acid) for calculation of ${ }^{14} \mathrm{C}$ age. The ratio of radioactivity of this secondary standard to that of the international standard is $1.362 \pm 0.002$, and the $\delta^{13} \mathrm{C}$ value of this secondary standard is $-19.32 \pm 0.56 \%$ with respect to the PDB standard belemnite.

\section{Data Analyses}

The probabilistic approach, in terms of Bayesian statistics, has emerged gradually and tends to become a leading method in ${ }^{14} \mathrm{C}$ calibration. Given the wiggly nature of the tree-ring calibration curve, this method deals with the relationship between a ${ }^{14} \mathrm{C}$ age and its corresponding calibrated ages in a probabilistic sense (Bronk Ramsey 1995). This is conceptually different from deterministic approaches, such as the intercept method. The advantage of the Bayesian method is that it can incorporate prior information about the calibrated age of a ${ }^{14} \mathrm{C}$ date into the calibration process, thereby significantly reducing the uncertainty of the calibrated age through extensive iterations using the Markov chain Monte Carlo (MCMC) algorithm. The most striking feature of the Bayesian-oriented calibration software (e.g. OxCal and $\mathrm{BCal}$ ) is the use of stratigraphic information of the ${ }^{14} \mathrm{C}$ dates to constrain the posterior probability of the calibrated age (Buck et al. 1992; Christen 1994; Buck and Christen 1998; Bayliss et al. 2007a; Bronk Ramsey 2008). Specifically, this method takes into account the stratigraphic context of these ${ }^{14} \mathrm{C}$ dates and expresses this stratigraphic relationship as a priori information, which is then incorporated into the tree-ring calibration process, thereby significantly reducing the uncertainty of the calibrated age. OxCal 3.0 (Bronk Ramsey 1995, 2001) was used to calibrate the ${ }^{14} \mathrm{C}$ dates. First, we grouped the ${ }^{14} \mathrm{C}$ dates into several archaeological phases according to typological characteristics of the stratigraphic units from which the ${ }^{14} \mathrm{C}$ dates were obtained. Then, we used the Sequence analysis module of this program to evaluate the stratigraphic consistency of the ${ }^{14} \mathrm{C}$ dates and perform the calibration. The calibrated dates were rounded to the nearest $10 \mathrm{yr}$ and reported as an age range with a $2-\sigma$ standard deviation.

\section{RESULTS}

\section{Lithological and Magnetic-Susceptibility Stratigraphies}

The Donglongshan site is located on the second terrace of the north bank of the upper Danjiang River. It is known to be the biggest site containing relics of the Xia Dynasty (possibly the first dynasty of China) in Shaanxi Province. A $2 \times 1.5 \mathrm{~m}^{2}$ archaeological trench running N-S was excavated near the center of the site. The southern exposure was sampled for ${ }^{14} \mathrm{C}$ dating, as well as geochemical and palynological analyses. The lithology and magnetic stratigraphy of this site is shown in Figure 1, and can be described as below. Unit $1(0-35 \mathrm{~cm})$ is a dark-brown modern soil with abundant plant roots and relatively low magnetic-susceptibility; Unit $2(35-60 \mathrm{~cm})$ is a brownish loose soil with higher magnetic susceptibility and contains rich charcoal and charred particles. Stone tools and gray potsherds are common, while red ceramic utensils are very rare; Unit 3 (60-100 
$\mathrm{cm})$ and Unit $4(100-130 \mathrm{~cm})$ form a paleosol dual complex with a firm structure and the highest magnetic susceptibility along the exposure. The upper layer is red-brown containing less iron-manganese nodules, whereas the lower one is dark red-brown with massive iron-manganese nodules and films. Earthworm burrows and root penetration can be seen in this layer. Unit $5(130-250 \mathrm{~cm})$ is a yellowish-brown Malan loess with a loose structure and relatively high magnetic susceptibility. Iron-manganese nodules with a diameter of $\sim 0.5 \mathrm{~cm}$ occur occasionally below $200 \mathrm{~cm}$.

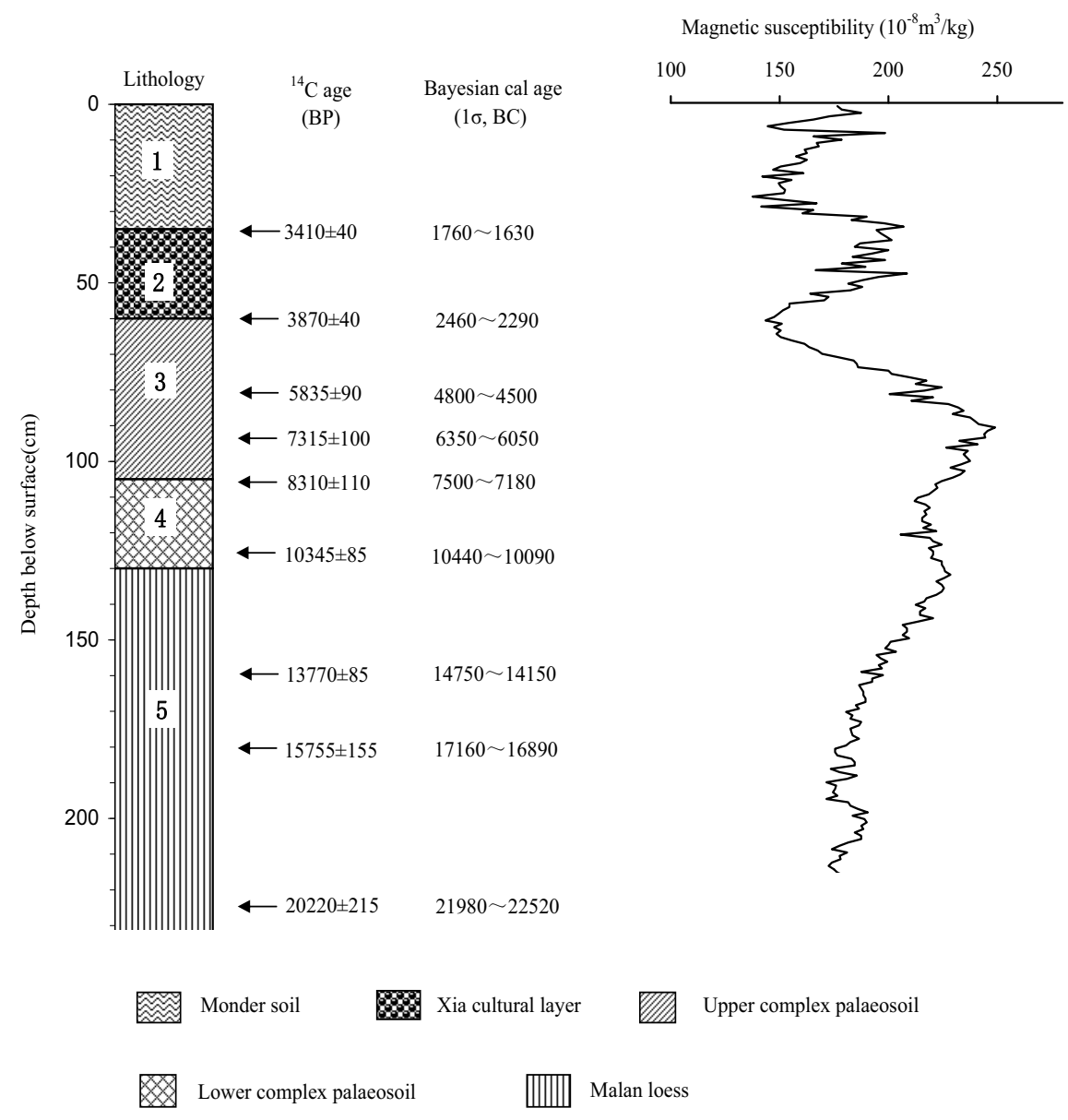

Figure 1 Lithologic and magnetic-susceptibility stratigraphies of the Donglongshan site. Numbers denote stratigraphical units. For details of these units and ${ }^{14} \mathrm{C}$ dates, see text and Table 1.

The Zijing site is situated on the second terrace of the south bank of the upper Danjiang River. This site represents the longest and most continuous known archaeological cultural sequence in the Shangluo area, consisting of the Yangshao and Longshan cultures, as well as the Xia, Shang, Zhou, Qin, and Han dynasties. A loess-paleosol exposure was also found nearby. Both the cultural layers of this site and the loess-paleosol sequence were sampled. Magnetic susceptibility was measured in the field at $\sim 2$-cm intervals as well (Figure 2). A detailed stratigraphical description of this archaeological site is given below. Unit $1(0-20 \mathrm{~cm})$ is a brownish modern soil with a loose structure and abundant plant roots. Unit $2(20-60 \mathrm{~cm})$ is a dark-brown loess layer containing white porcelain shards and pieces of gray tiles, probably from the Qin and Han dynasties. Units $3(60-110 \mathrm{~cm})$ and $4(110-$ 
Table 1 Pyrolytical ${ }^{14} \mathrm{C}$ dates of the Donglongshan archaeological site, Shangluo area of central China.

\begin{tabular}{|c|c|c|c|c|c|c|c|c|}
\hline \multirow[b]{2}{*}{$\begin{array}{l}\text { Depth } \\
(\mathrm{cm})\end{array}$} & \multirow[b]{2}{*}{ Lab code } & \multirow[b]{2}{*}{$\begin{array}{l}\text { Sample } \\
\text { code }\end{array}$} & \multicolumn{2}{|c|}{$400{ }^{\circ} \mathrm{C}$ fractions } & \multicolumn{2}{|c|}{$900^{\circ} \mathrm{C}$ fractions } & \multirow[b]{2}{*}{$\begin{array}{l}\text { True age } \\
\text { (yr BP) }\end{array}$} & \multirow[b]{2}{*}{$\begin{array}{l}\text { Bayesian } \\
\text { model age } \\
(1 \sigma, \mathrm{BC})\end{array}$} \\
\hline & & & $\begin{array}{l}\text { AMS } \\
{ }^{14} \mathrm{C} \text { age } \\
\text { (yr BP) }\end{array}$ & $\begin{array}{l}\text { MVC } \\
\text { age } \\
\text { (yr BP) }\end{array}$ & $\begin{array}{l}\text { AMS } \\
{ }^{14} \mathrm{C} \text { age } \\
(\mathrm{yr} B P)\end{array}$ & $\begin{array}{l}\text { MVC } \\
\text { age } \\
\text { (yr BP) }\end{array}$ & & \\
\hline 35 & AA78660 & DLSI35 & $3520 \pm 40$ & & $4100 \pm 40$ & & $3410 \pm 40^{\mathrm{a}}$ & $1760 \sim 1630$ \\
\hline 60 & AA78662 & DLSI60 & $3910 \pm 40$ & $3870^{\mathrm{a}}$ & $4160 \pm 40$ & $3870^{\mathrm{a}}$ & $3870 \pm 40^{\mathrm{a}}$ & $2456 \sim 2292$ \\
\hline 80 & AA78663 & DLSI80 & $4770 \pm 40$ & 5813 & $10,770 \pm 80$ & 5900 & $5856 \pm 90$ & 4832 4604 \\
\hline 95 & AA78664 & DLSI95 & $5040 \pm 50$ & 7270 & $10,260 \pm 90$ & 7422 & $7346 \pm 100$ & $6352 \sim 6080$ \\
\hline 105 & AA78665 & DLSI105 & $6740 \pm 60$ & 8241 & $11,350 \pm 90$ & 8437 & $8339 \pm 110$ & 7530 7194 \\
\hline 125 & AA78666 & DLSI125 & $8340 \pm 50$ & 10,183 & $13,070 \pm 70$ & 10,467 & $10,325 \pm 85$ & $10,426 \sim 10,051$ \\
\hline 160 & AA78667 & DLSI160 & $11,640 \pm 60$ & 13,583 & $16,780 \pm 170$ & 14,019 & $13,801 \pm 180$ & $14,777 \sim 14,192$ \\
\hline 180 & AA78668 & DLSI180 & $15,280 \pm 100$ & 15,526 & $18,520 \pm 120$ & 16,049 & $15,787 \pm 155$ & $17,186 \sim 16,917$ \\
\hline 225 & AA78669 & DLSI225 & $19,280 \pm 120$ & 19,896 & $24,000 \pm 180$ & 20,616 & $20,256 \pm 215$ & $22,568 \sim 22,014$ \\
\hline
\end{tabular}

${ }^{a}$ Date on charcoal, which is assumed to be the true age of a dated level.

$175 \mathrm{~cm}$ ) form a paleosol dual complex. The upper unit is a red-brownish paleosol with a loose structure and contains cultural remains of the Xia, Shang, and Zhou dynasties (occurring at $60-80 \mathrm{~cm}$ ) as well as the Longshan culture. An ash pit occurs at $80-110 \mathrm{~cm}$, which is partly filled with gray potsherds of the Longshan culture. The lower unit is a brownish loose paleosol containing red potsherds of the Yangshao culture as well as red soil concretes formed with the use of fire. Unit 5 (175-380 $\mathrm{cm}$ ) is marked by a layer of yellowish-brown loess-like sediments (i.e. the Malan loess) with a firm structure. There are not any cultural remains found in this unit. Calcareous nodules of various sizes are common at $\sim 200 \mathrm{~cm}$. The sediments below $350 \mathrm{~cm}$ are dominated by fluvial coarse sand and pebbles. Changes in magnetic susceptibility along this profile exhibit a cyclic pattern (Figure 2). Generally speaking, loess sediments (units 2 and 5) are characterized by lower magnetic susceptibility values, whereas the paleosol complex (units 3 and 4 ) is marked by higher magnetic susceptibility values.

\section{Chronology}

${ }^{14} \mathrm{C}$ dates of the low-temperature $\left(400{ }^{\circ} \mathrm{C}\right)$ and high-temperature $\left(900{ }^{\circ} \mathrm{C}\right)$ fractions are given in Table 1 for the Donglongshan site, along with modeled "true" ages using the mean value concept (MVC) as detailed in Zhou et al. (2007). According to the stratigraphic division from field observation, the Holocene/Pleistocene boundary lies at $\sim 130 \mathrm{~cm}$ depth. However, our dating of paleosol at a depth of $125 \mathrm{~cm}$ gives a ${ }^{14} \mathrm{C}$ age of $8340 \pm 50 \mathrm{yr} \mathrm{BP}$ for the low-temperature and $13,070 \pm 70 \mathrm{yr}$ $\mathrm{BP}$ for the high-temperature fraction, respectively (Table 1), indicating a potential contamination of younger and older carbon. Before applying Bayesian calibration to these raw ${ }^{14} \mathrm{C}$ dates, first we try to remove the contamination of average younger and older carbon using the MVC.

In the Donglongshan profile, the uppermost 60 -cm-thick strata is the modern plowing layer mixed with cultural remains, and ${ }^{14} \mathrm{C}$ dates from this layer are useless due to human disturbance. Therefore, we perform the regression calculation using ${ }^{14} \mathrm{C}$ ages of the low-temperature fraction from $60 \mathrm{~cm}$ down to $270 \mathrm{~cm}$. We obtain a model age of $2668 \mathrm{yr}$ at $60 \mathrm{~cm}$ depth. According to the MVC, this estimated age is the sum of the ${ }^{14} \mathrm{C}$ age and the average younger carbon age. Meanwhile, at $60 \mathrm{~cm}$ depth, we found a charcoal fragment that was taken from the lower boundary of the Xia cultural layer and dated to $3870 \pm 40 \mathrm{yr}$ BP. This date is consistent with the age of the Xia Dynasty (Xia-Shang-Zhou Dating Project Group 2000), indicating that the ${ }^{14} \mathrm{C}$ age of charcoal is reliable and presumably represents the true age of this level. Subtracting 2668 from 3870, we obtain a $\sim 1200$-yr error for the average younger carbon effect. In a like manner, our analyses for the ${ }^{14} \mathrm{C}$ ages of the high-tempera- 


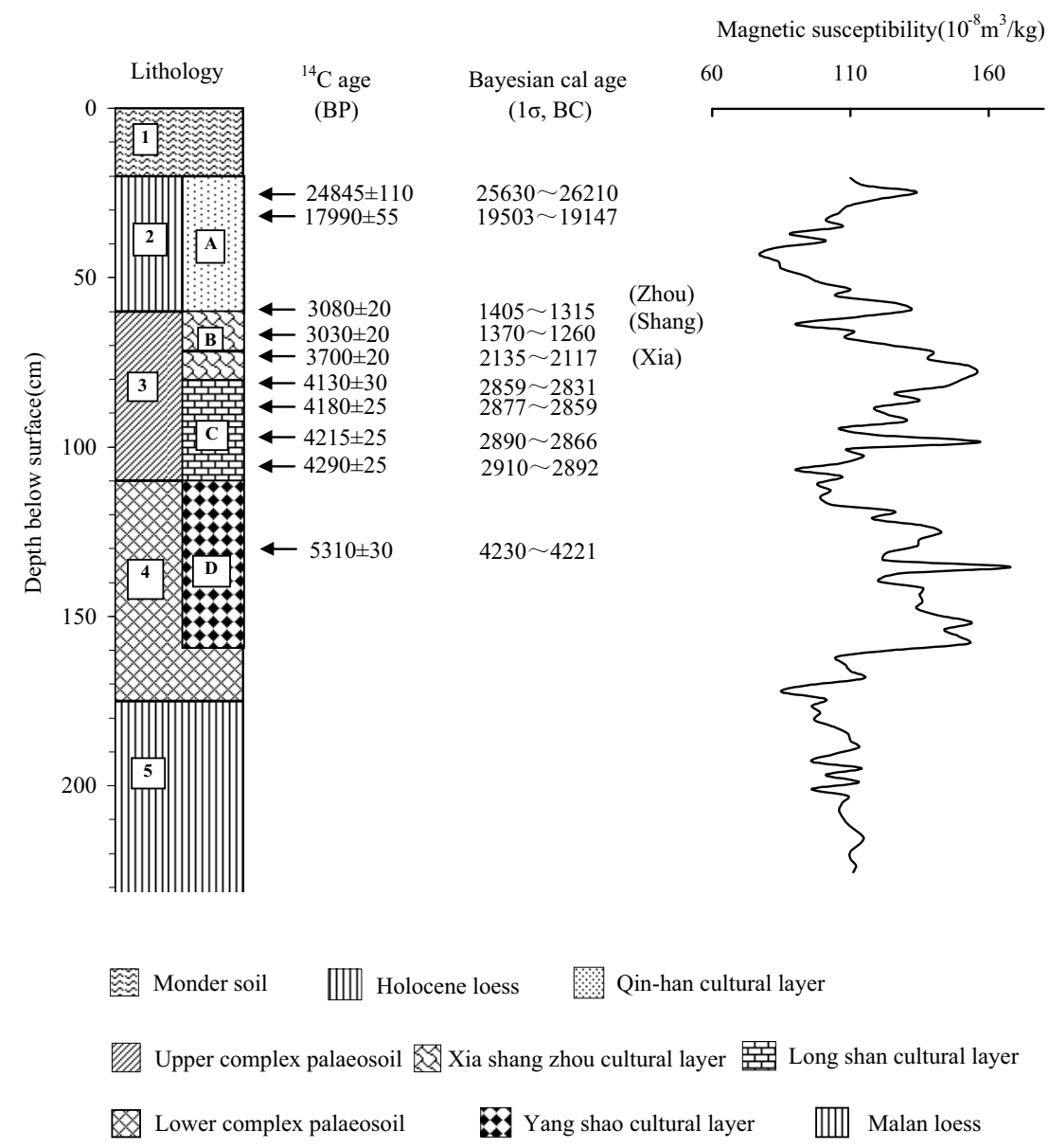

Figure 2 Lithologic and magnetic-susceptibility stratigraphies of the Zijing site. Numbers and letters denote stratigraphical and cultural units, respectively. For details of these units and ${ }^{14} \mathrm{C}$ dates, see text and Table 2 .

Table $2{ }^{14} \mathrm{C}$ dates of Zijing archaeological site, Qingling Mountains of central China. ${ }^{\text {a }}$

\begin{tabular}{llllllc}
\hline $\begin{array}{l}\text { Cultural } \\
\text { layer }\end{array}$ & Lab ID & $\begin{array}{l}\text { Sample } \\
\text { nr }\end{array}$ & $\begin{array}{l}\text { Depth } \\
(\mathrm{cm})\end{array}$ & $\begin{array}{l}\delta^{13} \mathrm{C} \\
(\% \text { vs PDB })\end{array}$ & $\begin{array}{l}{ }^{14} \mathrm{C} \text { age } \\
(\mathrm{BP})\end{array}$ & $\begin{array}{l}\text { Bayesian cal age } \\
(1 \text { })\end{array}$ \\
\hline Qin-Han & XA3253 & ZIJ25 & 25 & -25.67 & $24,845 \pm 110^{*}$ & $25,630-26,210 \mathrm{BC}$ \\
Qin-Han & XA3252 & ZIJ30 & 30 & -22.93 & $17,990 \pm 55^{*}$ & $19,500-19,150 \mathrm{BC}$ \\
Shang & XA3248 & ZIJ60 & 60 & -24.73 & $3080 \pm 20$ & $1410-1370 \mathrm{BC}$ \\
Shang & XA3260 & ZIJ65 & 65 & -26.15 & $3030 \pm 20$ & $1370-1350 \mathrm{BC}$ \\
Xia & XA3259 & ZIJ70 & 70 & -26.05 & $3700 \pm 20$ & $2135-2035 \mathrm{BC}$ \\
Longshan & XA3258 & ZIJ75 & 75 & -28.63 & $4130 \pm 30$ & $2860-2830 \mathrm{BC}$ \\
Longshan & XA3257 & ZIJ80 & 80 & -28.38 & $4220 \pm 25^{*}$ & $2890-2870 \mathrm{BC}$ \\
Longshan & XA3256 & ZIJ85 & 85 & -29.20 & $4180 \pm 25$ & $2880-2860 \mathrm{BC}$ \\
Longshan & XA3255 & ZIJ90 & 90 & -28.58 & $4240 \pm 25^{*}$ & $2900-2880 \mathrm{BC}$ \\
Longshan & XA3254 & ZIJ95 & 95 & -26.82 & $4215 \pm 25$ & $2890-2870 \mathrm{BC}$ \\
Yangshao & XA3268 & ZIJ105 & 105 & -26.11 & $4290 \pm 25$ & $2910-2890 \mathrm{BC}$ \\
Yangshao & XA3264 & ZIJ130 & 130 & -25.78 & $5310 \pm 30$ & $4230-4220 \mathrm{BC}$ \\
\hline
\end{tabular}

${ }^{a}$ Asterisks indicate dates rejected. 
ture fraction from $60 \mathrm{~cm}$ down to $270 \mathrm{~cm}$ yield an error of $2670 \mathrm{yr}$ for the average older carbon effect. Systematically removing these values of the carbon reservoir effect from the raw data, 2 sets of the "true" ${ }^{14} \mathrm{C}$ ages - one from the low-temperature fraction, the other from the high-temperature fraction - are obtained for the Donglongshan site (Table 1). Our results indicate that these 2 sets of ${ }^{14} \mathrm{C}$ chronologies are consistent with each other; with a deviation $<4 \%$ and match well with the stratigraphy. We simply take the mathematical mean of theses 2 data sets as the true age of the dated levels with $1-\sigma$ standard deviation defined by the square-root rule (see Table 1 ).

Regarding the calibration, we do not treat these samples individually. Rather, first we assemble the dates into a sequence according to their stratigraphic order, then we perform tree-ring calibration using the Bayesian Sequence analysis module of OxCal 3.0. The posterior distribution of the calibrated ${ }^{14} \mathrm{C}$ ages was obtained after 30,000 iterations, a point where the Markov chains converge. The results are presented in Table 1 as Bayesian modeled ages. Figure 3 illustrates how this method can yield a precise estimate of the calibrated age. As can be seen, the posterior distribution of the calibrated ${ }^{14} \mathrm{C}$ dates was substantially narrowed down compared to their prior distribution. Both the overall and individual agreement indices, the $A$ value parameter, exceed the threshold value (i.e. $60 \%$ ), suggesting a high coherency of this data set. Sample DLSI 125 was taken from the boundary between Malan loess and Holocene paleosol at this site. It is dated to 10,440-10,090 BC in this sequence. This date is compatible with the initiation of the Holocene epoch in the Loess Plateau (Liu 1985; Lei 1999). Sample DLSI60 was taken from the lower boundary of the Xia cultural layer. It is dated to 2460-2290 BC in this sequence, representing the onset of the Xia Dynasty. The termination of the Xia Dynasty can be determined by sample DLSI35, which was taken from the upper boundary of the Xia layer and dated to $1760-1630 \mathrm{BC}$ in this sequence.

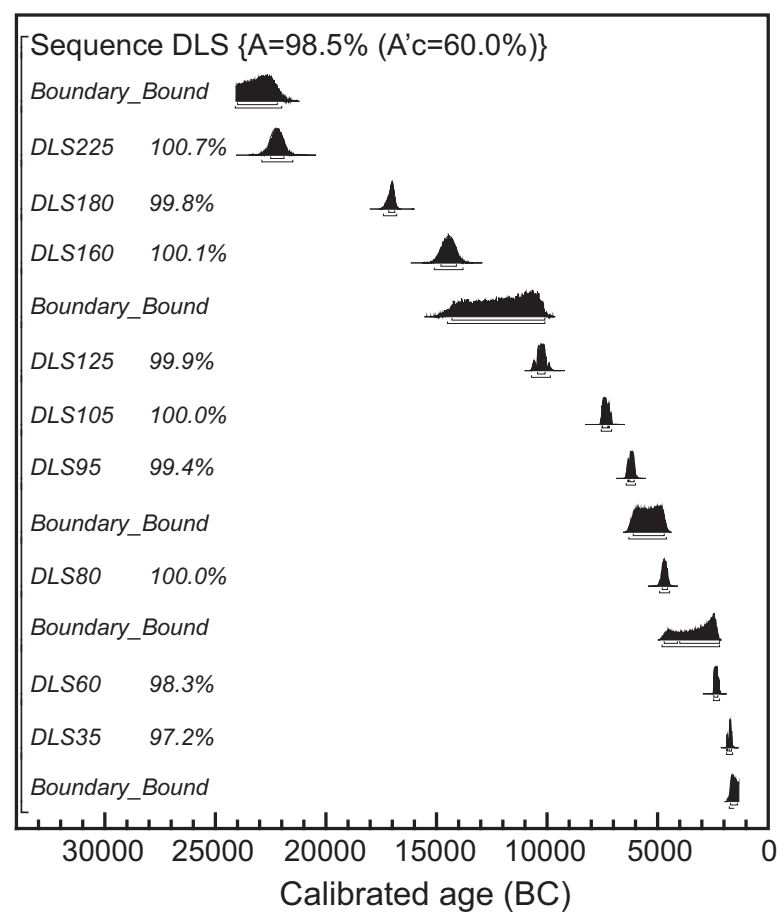

Figure 3 Bayesian tree-ring calibration of sequential ${ }^{14} \mathrm{C}$ dates for the Donglongshan site. 
The ${ }^{14} \mathrm{C}$ dates on charcoal and their Bayesian modeled ages are presented in Table 2 for the Zijing site. Note that the ages at 25 and $30 \mathrm{~cm}$ are significantly older than those underneath these depths. This reversal is due most likely to human disturbance. Therefore, caution should be taken when dating topsoil using charred particles. As with the Donglongshan dates, we obtain the tree-ring calibration by assembling the dates into a sequence according to their stratigraphic order. Results of the Bayesian analyses are presented in Figure 4. Note that the overall agreement index does not exceed the threshold value. This is caused by samples ZIJ80 and ZIJ90, which have a low $A$ value parameter and thus appear to be problematic. To increase the consistency, we remove these 2 outliers from the sequence, and then conduct Bayesian calibration again (Figure 5). As we can see in Figure 5, the agreement index increased to $81.2 \%$. Figure 5 and Table 2 show that the calibrated age of sample ZIJ130 in this sequence is $4230-4220 \mathrm{BC}$; this slightly postdates the beginning of the Yangshao culture, as expected since it was collected slightly above the lower boundary of Unit 4. Sample ZIJ105 was collected precisely at the boundary between the Yangshao and Longshan cultures (i.e. Units 4/ 3 ), and was dated to 2910-2890 BC. Therefore, the duration of the Yangshao culture can be determined to $\sim 4200-2900$ BC. Sample ZIJ70 gives a calibrated age of 2140-2120 BC. This provides a narrower constraint (i.e. $\sim 2100 \mathrm{BC}$ ) on the termination of the Longshan culture and hence the onset of the Xia Dynasty than that given by sample DLSI60 from the Donglongshan site.

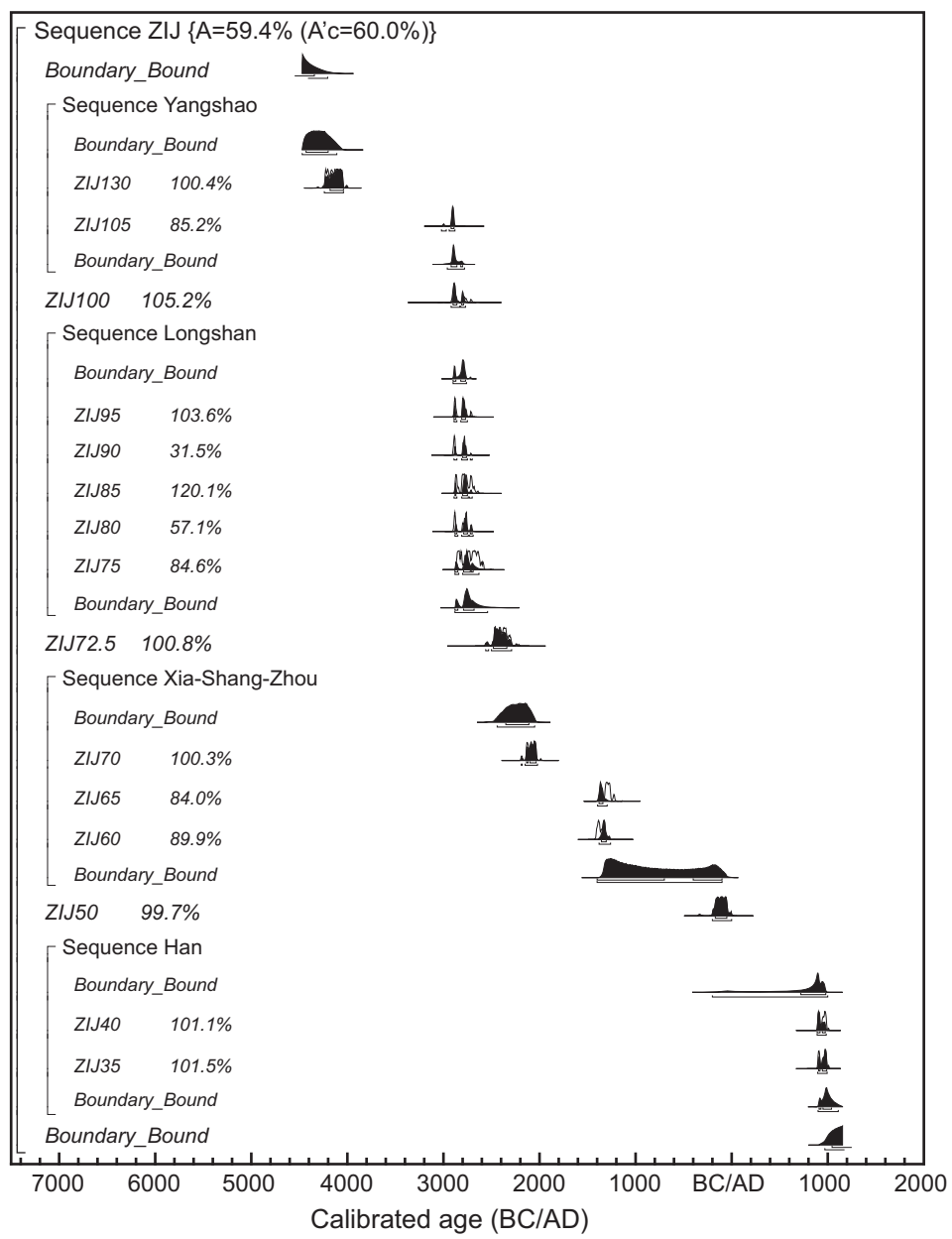

Figure 4 Bayesian tree-ring calibration of sequential ${ }^{14} \mathrm{C}$ dates for the Zijing site 


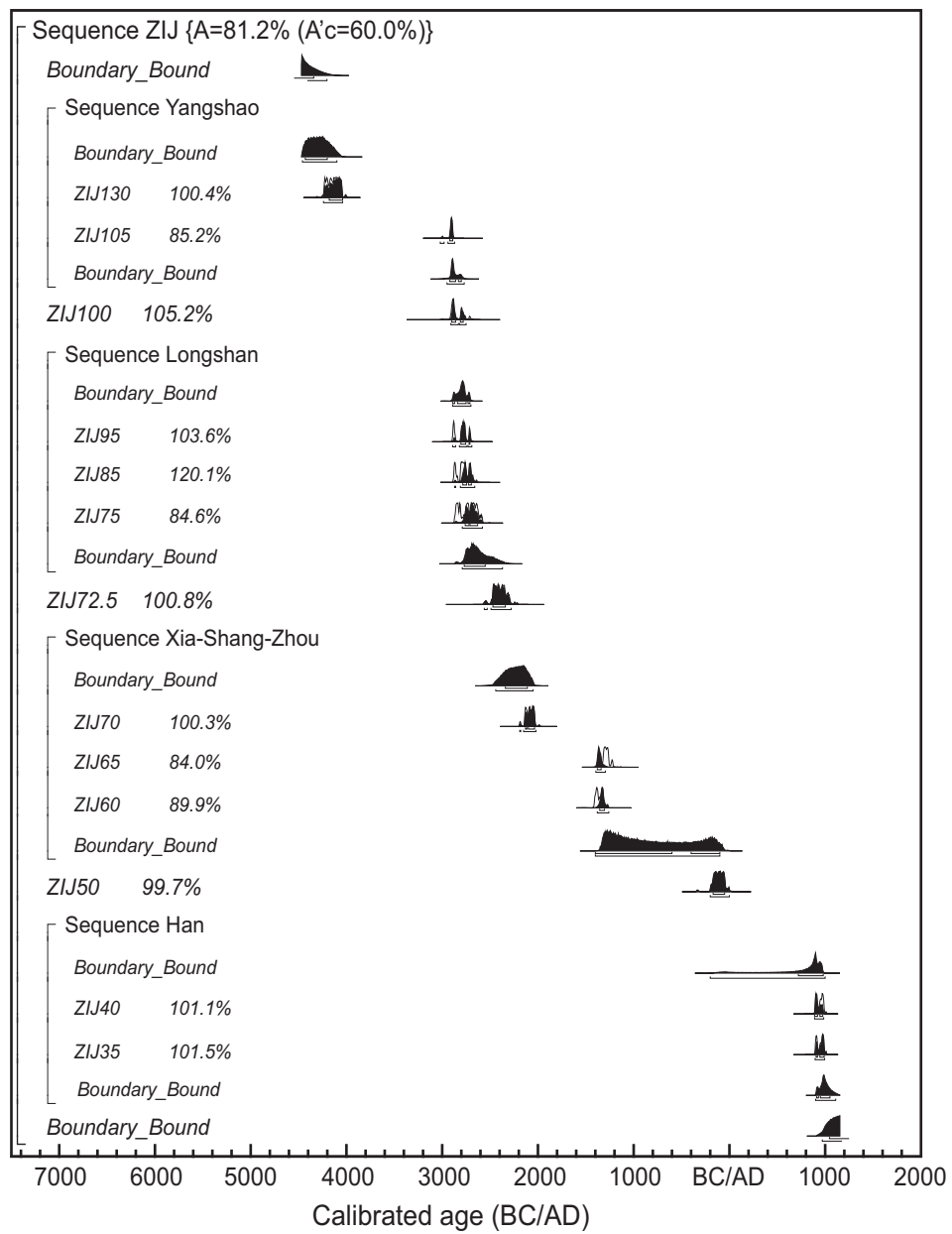

Figure 5 Bayesian tree-ring calibration of sequential ${ }^{14} \mathrm{C}$ dates for the Zijing site, after removing samples ZIJ80 and ZIJ90.

\section{DISCUSSION}

Detailed AMS ${ }^{14} \mathrm{C}$ dating and statistical analyses of both bulk soil and charcoal samples from the Donglongshan and Zijing sites provide a firm constraint on the timing of the Neolithic and early dynastic history of China in the Shangluo area of the Qingling Mountains. The Xia Dynasty has long been regarded as the first empire of China. However, the existence of the Xia Dynasty is very speculative because of the lack of detailed written and archaeological evidence. Thus, its duration is still debated in the archaeological community. Archaeological excavations at the Erlitou site, Henan Province, since the early 1960s tend to suggest a gradual transition from the Neolithic to the early dynastic period in the middle Yellow River area. This site is of great archaeological importance in the search for China's early dynastic history (Xu et al. 2007). The cultural sequence of this site can be subdivided into 4 stages. The first 2 stages are marked by the termination of the Neolithic and thus most likely can be correlated to the Xia Dynasty. The latter 2 stages represent the emergence of the Bronze Age as well as the origin of cities and nations corresponding to the Shang Dynasty. Nevertheless, debates still continue, and the key issues are about the societal structure and economic 
complexity of the Xia Dynasty if it existed in the form of a nation. Information from the Xia sites in the Shangluo area will provide new perspectives on this debate. For example, the surface decorative pattern of potsherds from the Xia layer of the Zijing and Erlitou sites is quite similar, implying that the Xia Dynasty may have existed, but most likely in the form of loosely united clans with a common cultural identity in central China.

Our chronology of the Holocene sediment sequence of the Donglongshan site is mainly based on bulk soil samples. In this study, only 2 combusted fractions were separated, which represents the end members of ${ }^{14} \mathrm{C}$-enriched and ${ }^{14} \mathrm{C}$-depleted carbon. For our age modeling, the younger and older carbon reservoir age was calculated separately using the mean value concept (MVC). After removing these errors, 2 sets of the true age for each sample were obtained. We take the average value of these 2 sets as the true age of the dated level. Our results indicate that this simple treatment can yield a precise estimate of the true age for each sample. For example, the transition of the Malan loessHolocene soil is well known as a regional stratigraphic marker, which represents the onset of the Holocene in central China (Liu 1985). This transition at the Donglongshan site was dated to 10,440$10,090 \mathrm{BC}$, which in general agrees with the accepted age for this event (Lei 1999). Our results for the onset of the Xia Dynasty are consistent with that proposed by the Xia-Shang-Zhou Dating Project Group (2000).

Our results reveal a continuous development of Neolithic and dynastic cultures in the Shangluo area of central China. However, it does not mean that there are no changes of the civilization in this area. Climatic changes during the Holocene may have exerted a strong impact on human livelihood in central China (Wu and Liu 2004) as in other parts of the world (Cullen et al. 2000; deMenocal 2001; Staubwasser et al. 2003). This is particularly true for the Neolithic people, as their economy totally relied on the availability of natural resources and climate conditions. Magnetic-susceptibility records of the Zijing and Donglongshan site show significant variations at each cultural transition. However, we are not sure whether these variations are caused by millennial-scale Holocene climate changes or human disturbances. Cultural remains at the Zijing site show a gradual change in economic style, from fishing-hunting-gathering to agriculture during the Neolithic. Both Heller and Liu (1982) and Liu et al. (1985) concluded that magnetic susceptibility can be taken as a proxy of paleoclimatic change in terms of variations of the Asian summer monsoon. High magnetic susceptibility correlates to a strong summer monsoon, whereas low magnetic susceptibility correlates to a weak summer monsoon. This cultural succession could be possibly ascribed to climate forcing, e.g. the gradual retreat of the summer monsoon front during the Late Holocene. For example, widespread paleosols, corresponding to high magnetic-susceptibility values, developed in central China prior to $\sim 2100 \mathrm{BC}$, indicating warmer and wetter monsoonal climate conditions than those of today. This climate setting provides favorable living conditions for the Neolithic people. Regional climate then became dry and cold from $\sim 2100 \mathrm{BC}$ when the Xia Dynasty started, as loess started to accumulate again. Crop remains at the Zijing site indicate that agriculture had to be introduced to deal with the shortage of natural resources. This severe climatic interval can be correlated to the substantial decay of the Asian summer monsoon (Wang et al. 2005; Yancheva et al. 2007), which ultimately pushed China's Neolithic civilization into the dynastic period.

\section{CONCLUSIONS}

Detailed AMS ${ }^{14} \mathrm{C}$ dating and statistical analyses of cultural layers within the stratigraphic context of loess-paleosol sequences at 2 sites yield a reliable chronological framework for Neolithic and early dynastic archaeology in the Shangluo area of central China. Our results reveal a continuous human occupation in this area during the second half of the Holocene. The development of regional 
Neolithic and early dynastic cultures experienced 3 stages from the Yangshao ( 4200-2900 BC), through the Longshan ( 2900-2100 BC), to the Xia-Shang-Zhou dynasties. A close correlation of this cultural sequence with the loess-paleosol sequence suggests that climate may have played a major role in the rise and fall of civilization in this area. The Yangshao and Longshan cultures developed under warm and wet climate conditions, indicated in the stratigraphic sequence as a continuous pedogenetic process during the middle Holocene. A significant change in regional climate conditions occurred at $\sim 2100 \mathrm{BC}$, as marked by the transition from paleosol to loess in the stratigraphic sequence. This climatic shift from warm and wet to cold and dry conditions coincides with the termination of the Neolithic and the emergence of dynastic civilization in this area.

\section{ACKNOWLEDGMENTS}

This work was supported by the National Science Foundation of China (grant nr 40773079) and the MOST special fund for the State Key Laboratory of Loess and Quaternary Geology (LQ0705). We thank C F Wang at the Museum of Shang County for assistance during fieldwork. Our gratitude is also extended to the anonymous reviewers for their constructive comments and suggestion.

\section{REFERENCES}

Aguilar DGP, Litton CD, O’Hagan A. 2002. Novel statistical model for a piece-wise linear radiocarbon calibration curve. Radiocarbon 44(1):195-212.

Bayliss A, Benson D, Galer D, Humphrey L, McFadyen L, Whittle A. 2007a. One thing after another: the date of the Ascott-under-Wychwood long barrow. Cambridge Archaeological Journal 17(S1):29-44.

Bayliss A, Bronk Ramsey C, van der Plicht J, Whittle A. 2007b. Bradshaw and Bayes: towards a timetable for the Neolithic. Cambridge Archaeological Journal 17(S1):1-28.

Beramendi-Orosco LE, Gonzalez-Hernandez G, UrrutiaFucugauchi J, Manzanilla LR, Soler-Arechalde AM, Goguitchaishvili A, Jarboe N. 2009. High-resolution chronology for the Mesoamerican urban center of Teotihuacan derived from Bayesian statistics of radiocarbon and archaeological data. Quaternary Research 71(2):99-107.

Blaauw M, Christen JA. 2005. Radiocarbon peat chronologies and environmental change. Applied Statistics 54(4):805-16.

Blaauw M, Bakker R, Christen JA, Hall VA, van der Plicht J. 2007. A Bayesian framework for age modeling of radiocarbon-dated peat deposits: case studies from the Netherlands. Radiocarbon 49(2):357-67.

Blackwell PG, Buck CE. 2003. The Late Glacial human reoccupation of north-western Europe: new approaches to space-time modelling. Antiquity 77:232 40.

Boaretto E, Wu X, Yuan J, Bar-Yosef O, Chu V, Pan Y, Liu K, Cohen D, Jiao T, Li S, Gu H, Goldberg P, Weiner S. 2009. Radiocarbon dating of charcoal and bone collagen associated with early pottery at Yuchanyan Cave, Hunan Province, China. Proceedings of the National Academy of Sciences of the USA 106:9595600.
Bronk Ramsey C. 1995. Radiocarbon calibration and analysis of stratigraphy: the OxCal program. Radiocarbon 37(2):425-30.

Bronk Ramsey C. 2001. Development of the radiocarbon calibration program. Radiocarbon 43(2A):355-63.

Bronk Ramsey C. 2008. Deposition models for chronological records. Quaternary Science Reviews 27(1-2): 42-60.

Bronk Ramsey C. 2009. Bayesian analysis of radiocarbon dates. Radiocarbon 51(1):337-60.

Bronk Ramsey C, van der Plicht J, Weninger B. 2001. 'Wiggle matching' radiocarbon dates. Radiocarbon 43(2A):381-9.

Buck CE, Christen JA. 1998. A novel approach to selecting samples for radiocarbon dating. Journal of Archaeological Science 25(4):303-10.

Buck CE, Kenworthy JB, Litton CD, Smith AFM. 1991. Combining archaeological and radiocarbon information: a Bayesian approach to calibration. Antiquity 65 : 808-21.

Buck CE, Litton CD, Smith AFM. 1992. Calibration of radiocarbon results pertaining to related archaeological events. Journal of Archaeological Science 19(5): 497-512.

Buck CE, Higham TFG, Lowe DJ. 2003. Bayesian tools for tephrochronology. The Holocene 13(5):639-47.

Buck CE, Aguilar DGP, Litton CD, O’Hagan A. 2006. Bayesian nonparametric estimation of the radiocarbon calibration curve. Bayesian Analysis 1(2):265-88.

Christen JA. 1994. Summarizing a set of radiocarbon determinations: a robust approach. Applied Statistics 43(3):489-503.

Christen JA, Litton CD. 1995. A Bayesian approach to wiggle-matching. Journal of Archaeological Science 22(6):719-25.

Christen JA, Clymo RS, Litton CD. 1995. A Bayesian 
approach to the use of ${ }^{14} \mathrm{C}$ dates in the estimation of the age of peat. Radiocarbon 37(2):431-41.

Cullen HM, deMenocal PB, Hemming S, Hemming G, Brown FH, Guilderson T, Sirocko F. 2000. Climate change and the collapse of the Akkadian empire: evidence from the deep sea. Geology 28(4):379-82.

deMenocal PB. 2001. Cultural responses to climate change during the late Holocene. Science 292(5517): $667-73$.

Fuller DQ, Boivin N, Korisettar R. 2007. Dating the Neolithic of South India: new radiometric evidence for key economic, social and ritual transformations. Antiquity 81:755-78.

Goslar T, Madry W. 1998. Using the Bayesian method to study the precision of dating by wiggle-matching. $R a$ diocarbon 40(1):551-60.

Heller F, Liu T-S. 1982. Magnetostratigraphical dating of loess deposits in China. Nature 300(5891):431-3.

Higham C, Higham T. 2009. A new chronological framework for prehistoric Southeast Asia, based on a Bayesian model from Ban Non Wat. Antiquity 83:125-44.

Library of Shang County, Banpo Museum of Xian. 1983. Excavation report of Zijing archaeological site: Shang County of Shaanxi Province. Archaeology and Cultural Relics 3:33-47. In Chinese.

Lei XY. 1999. Paleoenvironmental changes recorded by Shangzhou loess-paleosol sequences on the eastern Qinling Mts. during the last 0.6Ma. Marine Geology and Quaternary Geology 19:63-73. In Chinese.

Liu T-S. 1985. Loess and Environment. Beijing: Science Press. p 62-81. In Chinese.

Lowe DJ, Shane PAR, Alloway BV, Newnham RM. 2008. Fingerprints and age models for widespread New Zealand tephra marker beds erupted since 30,000 years ago: a framework for NZ-INTIMATE. Quaternary Science Reviews 27(1-2):95-126.

Lowe JJ, Blockley S, Trincardi F, Asioli A, Cattaneo A, Matthews IP, Pollard M, Wulf S. 2007. Age modelling of late Quaternary marine sequences in the Adriatic: towards improved precision and accuracy using volcanic event stratigraphy. Continental Shelf Research 27(3-4):560-82.

Navarro N. 2005. Incorporating $\delta^{18} \mathrm{O}$ values of past waters in the calibration of radiocarbon dating. Geology 33(5):369-72.

Nicholls G, Jones M. 2001. Radiocarbon dating with temporal order constraints. Applied Statistics 50(4):50321.

Palonen V, Tikkanen P. 2007. Pushing the limits of AMS radiocarbon dating with improved Bayesian data analysis. Radiocarbon 49(2):1261-72.

Petrie CA, Torrence R. 2008. Assessing the effects of volcanic disasters on human settlement in the Willaumez Peninsula, Papua New Guinea: a Bayesian approach to radiocarbon calibration. The Holocene 18(5):729-44.
Scharer KM, Weldon RJ, Fumal TE, Biasi GP. 2007. Paleoearthquakes on the Southern San Andreas Fault, Wrightwood, California, 3000 to 1500 B.C.: a new method for evaluating paleoseismic evidence and earthquake horizons. Bulletin of the Seismological Society of America 97(4):1054-93.

Staubwasser M, Sirocko F, Grootes PM, Segl M. 2003. Climate change at the $4.2 \mathrm{ka}$ BP termination of the Indus valley civilization and Holocene south Asian monsoon variability. Geophysical Research Letters 30(8):1425, doi:10.1029/2002GL016822.

Steier P, Rom W. 2000. The use of Bayesian statistics for ${ }^{14} \mathrm{C}$ dates of chronologically ordered samples: a critical analysis. Radiocarbon 42(2): 183-98.

Wang Y, Cheng H, Edwards RL, He Y, Kong X, An Z, Wu J, Kelly MJ, Dykoski CA, Li X. 2005. The Holocene Asian monsoon: links to solar changes and North Atlantic climate. Science 308(5723):854-7.

Xia-Shang-Zhou Dating Project Group. 2000. Report of Xia-Shang-Zhou Dating Project, 1996-2000. Beijing: Shijie Tushu Publishing. p 11-23. In Chinese.

Wu WX, Liu T-S. 2004. Possible role of the "Holocene Event 3" on the collapse of Neolithic cultures around the Central Plain of China. Quaternary International 117(1):153-66.

Xu H, Zhao HT, Chen GL. 2007. Erlitou Archaeological Site. Beijing: Press of Cultural Relics. p 35-52. In Chinese.

Yancheva G, Nowaczyk NR, Mingram J, Dulski P, Schettler G, Negendank JFW, Liu J, Sigman DM, Peterson LC, Haug GH. 2007. Influence of the intertropical convergence zone on the East Asian monsoon. Nature 445(7123):74-7.

Yang YC. 2003. Ancient Cultures and Environment in the Upper Danjiang River Area. Xi'an: Sanqin Press. p 371-5. In Chinese.

Zeidler JA, Buck CE, Litton CD. 1998. Integration of archaeological phase information and radiocarbon results from the Jama River Valley, Ecuador: a Bayesian approach. Latin American Antiquity 9(2):160-79.

Zhang XL, Qiu SH, Cai LZ. 2007. Establishing and refining the archaeological chronology for Erlitou-Erligang cultures. Archaeology 8:74-89. In Chinese.

Zhou WJ, Zhou MF, Head MJ. 1990. ${ }^{14} \mathrm{C}$ chronology of Beizhuangcun sedimentation sequence since 30,000 years B.P. Chinese Science Bulletin 35:567-72.

Zhou WJ, An ZS, Lin BH, Xiao JL, Zhang JZ, Xie J, Zhou MF, Porter SC, Head MJ, Donahue DJ. 1992. Chronology of the Baxie loess profile and the history of monsoon climates in China between 17,000 and 6000 years BP. Radiocarbon 34(3):818-25.

Zhou WJ, Chen MB, Xian F, Song SH, Wu ZK, Jull AJT, Liu WG. 2007. The mean value concept in mono-linear regression of multi-variables and its application to trace studies in geosciences. Science in China Series D-Earth Sciences 50(12):1828-34. 